\title{
Surgical Outcomes Following Early Drain Removal After Distal Pancreatectomy in Elderly Patients
}

\author{
TERUHISA SAKAMOTO, YAKUKI YAGYU, EI UCHINAKA, TAKEHIKO HANAKI, \\ KOZO MIYATANI, KYOICHI KIHARA, MANABU YAMAMOTO, TOMOYUKI MATSUNAGA, \\ NARUO TOKUYASU, SOICHIRO HONJO and YOSHIYUKI FUJIWARA \\ Division of Gastrointestinal and Pediatric Surgery, Department of Surgery, \\ School of Medicine, Tottori University Faculty of Medicine, Yonago, Japan
}

\begin{abstract}
Background/Aim: The efficacy and safety of early drain removal following distal pancreatectomy in elderly patients are unclear. We aimed to investigate the short-term surgical outcomes following early drain removal after distal pancreatectomy in elderly patients. Patients and Methods: Fifty-seven patients aged $\geq 70$ years who underwent distal pancreatectomy at our Hospital were enrolled in the study. Data were retrospectively analyzed to evaluate the short-term surgical outcomes following early drain removal after distal pancreatectomy in elderly patients. Results: The incidence of pancreatic fistula following distal pancreatectomy in the early-removal group was significantly lower vs. the conventional group $(p=0.022)$. Multivariate analysis revealed that early drain removal was an independent factor for reducing the risk of pancreatic fistula after distal pancreatectomy in elderly patients $(p=0.042)$. Conclusion: Early drain removal following distal pancreatectomy is an effective and safe surgical perioperative management procedure to prevent pancreatic fistula in elderly patients.
\end{abstract}

General surgery for elderly patients has been increasing with aging populations, worldwide (1). Additionally, pancreatic resection for elderly patients has been gradually accepted because the surgical outcomes after pancreatectomy were not inferior compared to younger patients (2-5).

Distal pancreatectomy (DP) for benign or malignant disease located in the left pancreas is considered a safe surgical

This article is freely accessible online.

Correspondence to: Teruhisa Sakamoto, Division of Gastrointestinal and Pediatric Surgery, Department of Surgery, School of Medicine, Tottori University Faculty of Medicine, 36-1 Nishi-cho, Yonago 683-8504, Japan. Tel: +81 859386567, Fax: +81 859386569, e-mail: tesakamo@tottori-u.ac.jp

Key Words: Distal pancreatectomy, early drain removal. procedure, with low mortality of $0-0.3 \%$ with recent advances in surgical techniques and management; however, morbidity associated with DP remains high (6). Pancreatic fistula is one of the main complications after DP, occurring in $18-39 \%$ of patients undergoing DP, and can lead to intra-abdominal abscess or postoperative hemorrhage, which prolong the length of postoperative hospital stay and increase medical costs (6-9). Regarding elderly patients with organ functional impairment or frailty, even if not fatal, pancreatic fistula is a more serious complication compared to younger patients because of the possibility of postoperative loss of independence caused by pancreatic fistula. Therefore, safer surgical procedures or perioperative management are needed to minimize the incidence of pancreatic fistula after DP in elderly patients.

Although several randomized control trials closed the stump of remnant pancreas to attempt to decrease pancreatic fistula after DP, no definitive methods exist to prevent or decrease postoperative pancreatic fistula after DP (10-13).

Recently, early drain removal has been reported to effectively reduce the incidence of postoperative pancreatic fistula after DP $(14,15)$. However, the surgical outcomes of early drain removal after DP in elderly patients are uncertain. Considering population aging (16), studies involving only elderly patients are needed. Therefore, we aimed to assess the short-term surgical outcomes following early drain removal after DP compared with conventional drain removal in a cohort of only elderly patients.

\section{Patients and Methods}

Patients. Between August 2010 and August 2019, 95 patients underwent DP at the Tottori University Hospital. We considered patients aged $\geq 70$ years as elderly patients (17), and we reviewed data for 58 patients $(61.1 \%)$ aged $\geq 70$ years of the 95 patients undergoing DP. Of the 58 patients, we enrolled 57 patients who underwent DP using a stapler to transect the pancreatic parenchyma. We excluded one patient because the parenchyma was transected using an ultrasonically-activated device at the right side of the portal vein. 
The Institutional Review Board of approved this retrospective study (No. 17A135) and waived the requirement for informed consent in this retrospective study.

Determining the pancreatic transection line and measuring pancreatic thickness. We determined the pancreatic transection line by assessing the tumor location using preoperative multidetector-row computed tomography in the portal phase. Generally, we divided the pancreatic parenchyma above the portal vein. However, in patients with lowgrade malignant tumors or metastatic tumors or benign disease located in the pancreatic tail, we shifted the transection line toward the pancreatic tail $v s$. the left edge of the portal vein. The final decision regarding the transection line was made intraoperatively by the surgeon according to the intraoperative ultrasonographic findings, to obtain safe surgical margins. The thickness of the expected pancreatic transection line was measured preoperatively using the axial view in the preoperative multidetector-row computed tomographic images

Closing the pancreatic stump and inserting the drain. After January 2017, in all but one patient, we transected the pancreatic parenchyma using the Endo GIA tri-staple (Covidien, Tokyo, Japan), which is a triple-row stapler reinforced with a polyglycolic acid sheet (Neoveil ${ }^{\circledR}$; GUNZE, Kyoto, Japan). One patient underwent pancreatic transection using the Endo GIA tri-staple without a polyglycolic acid sheet. From August 2010 to December 2016, we used an Endo GIA tri-staple with reinforcement for 4 patients and without reinforcement for 26 patients. We used the Endo GIA with double-row staples (Covidien) with reinforcement in seven patients. We used the Echelon 60 (Ethicon Endo-Surgery, Cincinnati, OH, USA), which is a triple-row stapler, with a green cartridge and $4.3-\mathrm{mm}$ staple height, to divide the pancreatic parenchyma in one patient. Regarding the Endo GIA stapler, one of three cartridge types was selected depending on the thickness of the expected pancreatic transection line. We used the black cartridge with a 4.0-5.0-mm staple height for pancreatic parenchyma $\geq 10 \mathrm{~mm}$ thick and a purple cartridge with a $3.0-4.0-\mathrm{mm}$ staple height for pancreatic parenchyma $<10 \mathrm{~mm}$. From August 2010 to July 2011, we used a green cartridge with a $4.3-\mathrm{mm}$ staple height to divide the pancreatic parenchyma, regardless of the pancreatic thickness. The pancreas was compressed slowly for more than 10 minutes and transected carefully over $5 \mathrm{~min}$. We then examined the stump of the remnant pancreas, namely, the staple line at the stump or the pancreatic parenchyma near the stump. Pancreatic parenchymal injury to the remnant pancreas and hemorrhage along the staple line were repaired immediately, if present. After peritoneal lavage, we placed a closed drain near the stump of the remnant pancreas. If necessary, another drain was placed in the left subphrenic space.

Postoperative management. Prophylactic antibiotics were administered until postoperative day (POD) 2 or earlier in all patients. Oral intake was started on POD 3 or 4 if no severe postoperative surgical complications occurred, such as severe pneumonia or paralytic ileus. Routinely, we measured the drain amylase level on POD 1 and 3. We also performed bacterial culture and a bacterial smear test of the drainage fluid to detect infection on POD 1 and 3. Regarding the criteria for removing the drain in our institution, from August 2010 to December 2016, we removed the drain on POD 3 or 4 if the amylase level in the drainage fluid on POD 3 was less than three times the serum value or less than < $800 \mathrm{IU} / 1$ as an absolute value, and the drainage fluid was clear. After
Table I. Overall patient clinicopathological variables.

\begin{tabular}{lc}
\hline & $\mathrm{n}=57$ \\
\hline Age, median (range), (year) & $77(70-87)$ \\
Gender (n, \%) & \\
Male & $38(66.7 \%)$ \\
Female & $19(33.3 \%)$ \\
Body mass index, median (range), $\left(\mathrm{kg} / \mathrm{m}^{2}\right)$ & $21.3(14.0-28.8)$ \\
Histological diagnosis (n, \%) & \\
Pancreatic ductal adenocarcinoma & $31(54.4 \%)$ \\
Acinar cell cancer & $1(1.8 \%)$ \\
IPMN & $11(19.3 \%)$ \\
ITPN & $1(1.8 \%)$ \\
PNEN & $5(8.8 \%)$ \\
MCN & $2(3.5 \%)$ \\
SPN & $1(1.8 \%)$ \\
Metastatic pancreatic tumor & $2(3.5 \%)$ \\
Other disease & $3(5.3 \%)$ \\
Surgical approach (n, \%) & \\
Laparoscopy & $12(21.1 \%)$ \\
Spleen preservation (n, \%) & \\
Present & $2(3.5 \%)$ \\
Absent & $55(96.5 \%)$ \\
Thickness of the pancreatic transection, & \\
median (range), (mm) & $11.1(4.0-20.4)$ \\
Type of stapler (n, \%) & \\
Triple-row stapler & $50(87.7 \%)$ \\
Double-row stapler & $7(12.3 \%)$ \\
Reinforcement (n, \%) & \\
Present & $29(50.9 \%)$ \\
Absent & $28(49.1 \%)$ \\
Pancreatic fistula, (n, \%) & $17(29.8 \%)$ \\
\hline
\end{tabular}

IPMN, Intraductal papillary mucinous neoplasm; ITPN, intraductal tubulopapillary neoplasm; PNEN, pancreatic neuroendocrine neoplasm; MCN, mucinous cystic neoplasm; SPN, solid pseudopapillary neoplasm. Continuous variables are expressed as median with range.

POD 5, the drain was maintained until the postoperative pancreatic fistula resolved, according to the judgment of the chief hepatobiliary-pancreatic surgeon in our institution. We considered the patients receiving drain removal according to this old criteria to constitute the conventional group. In contrast, after January 2017, we removed the drain on POD 3 or 4, regardless of the amylase level and drainage fluid volume, if infection was confirmed to be absent according to the bacterial smear test performed on POD 3. We considered the patients receiving drain removal based on the new criteria to constitute the early removal group.

Definition of pancreatic fistula after DP. Pancreatic fistula was defined according to the definition of the International Study Group on Pancreatic Surgery (18). Namely, in this study, we defined pancreatic fistula as follows; persistent drainage of $>3$ weeks, reinsertion of an intra-abdominal drain, and angiographic procedures for hemorrhage, which were classified as grade B, and reoperation classified as grade $\mathrm{C}$.

Clinicopathological variables. We collected data for the following clinicopathological variables from the patients' medical records: age, 
Table II. Comparison of preoperative and intraoperative clinicopathological variables in elderly patients undergoing distal pancre-atectomy between the early drain removal group and the conventional drain removal group.

\begin{tabular}{|c|c|c|c|}
\hline Variable & Early removal group $(n=19)$ & Conventional group $(n=38)$ & $p$-Value \\
\hline Age, median (range), (year) & $78.0(70-87)$ & $77.0(70-87)$ & 0.541 \\
\hline Gender, male (n, \%) & $11(57.9 \%)$ & $27(71.1 \%)$ & 0.321 \\
\hline Body mass index, median (range), $\left(\mathrm{kg} / \mathrm{m}^{2}\right)$ & $21.4(18.0-27.8)$ & $21.2(14.0-28.8)$ & 0.553 \\
\hline Histological diagnosis (n, \%) & & & 0.132 \\
\hline Pancreatic ductal adenocarcinoma & $13(68.4 \%)$ & $18(47.4 \%)$ & \\
\hline Other disease & $6(31.6 \%)$ & $20(52.6 \%)$ & \\
\hline Preoperative prognostic nutritional index, median (range) & $48.2(40.7-69.1)$ & $49.0(19.8-59.2)$ & 0.919 \\
\hline Operative time, median (range), (min) & $345(272-537)$ & $345.5(175-779)$ & 0.226 \\
\hline Intraoperative blood loss volume, median (range), (ml) & $240(15-1,285)$ & $405(10-1,565)$ & 0.119 \\
\hline \multicolumn{4}{|l|}{ Surgical approach $(\mathrm{n}, \%)$} \\
\hline Laparoscopy & $7(36.8 \%)$ & $5(13.2 \%)$ & 0.045 \\
\hline Spleen preservation $(\mathrm{n}, \%)$ & & & 0.440 \\
\hline Present & $0(0 \%)$ & $2(5.3 \%)$ & \\
\hline Absent & $19(100.0 \%)$ & $36(94.7 \%)$ & \\
\hline Thickness of the pancreatic transection line, median (range) (mm) & $11.7(8.8-17.1)$ & $11.1(4.0-20.4)$ & 0.525 \\
\hline Type of stapler (n, \%) & & & 0.048 \\
\hline Triple-row stapler & $19(100.0 \%)$ & $31(81.6 \%)$ & \\
\hline Double-row stapler & $0(0 \%)$ & $7(18.4 \%)$ & \\
\hline Reinforcement (n, \%) & & & $<0.001$ \\
\hline Present & $18(94.7 \%)$ & $11(28.9 \%)$ & \\
\hline Absent & $1(5.3 \%)$ & $27(71.7 \%)$ & \\
\hline Combined with gastrectomy, colectomy, enterectomy (n, \%) & $0(0 \%)$ & $6(15.8 \%)$ & 0.076 \\
\hline
\end{tabular}

Continuous variables are expressed as median with range.

sex, body mass index (BMI), histological diagnosis, preoperative prognostic nutritional index, operation time, intraoperative blood loss volume, surgical approach, spleen preservation, thickness of the pancreatic transection line, type of stapler, use of reinforcement, combined with gastrectomy or colectomy or enterectomy, drain amylase levels and serum C-reactive protein levels on POD 1 and 3, bacterial culture and bacterial smear tests of the drainage fluid on POD 1 and 3, duration of drain insertion, length of postoperative hospital stay, postoperative fluid collection at the stump of the remnant pancreas $\geq 3$ months postoperatively, readmission and mortality within 90 days after surgery, and pancreatic fistula.

Statistical analysis. The continuous variables were expressed as median with range, and categorical variables were expressed as number (proportions, \%). The Chi-square test, Fisher's exact test, and the Mann-Whitney $U$-test were used to evaluate differences in the clinicopathological variables between the two groups. We used receiver operating characteristic curve analysis to determine the cutoff value for the thickness of the pancreatic transection line. Univariate and multivariate logistic regression analyses were performed to clarify the risk factors for pancreatic fistula after DP. $p<0.05$ was considered statistically significant, and all statistical analyses were performed using SPSS software (Version 24; IBM Corp., Armonk, NY, USA).

\section{Results}

Overall, patient characteristics are summarized in Table I. The median patient age was 77 years (range $=70-87$ years) and the male:female ratio was 2:1. The median BMI was
$21.3($ range $=14.0-28.8) \mathrm{kg} / \mathrm{m}^{2}$. This study included 31 patients $(54.4 \%)$ diagnosed as having pancreatic ductal adenocarcinoma histologically. Laparoscopic surgery was performed in $12 / 57(12.1 \%)$ patients, and two patients (3.5\%) underwent DP with spleen preservation. The median thickness of the pancreatic transection line was $11.0 \mathrm{~mm}$ (range $=4.0-20.4 \mathrm{~mm}$ ). A triple-row stapler was used to divide the pancreas in 50 patients $(87.7 \%)$, and reinforcement was used in 29 patients $(50.9 \%)$. Pancreatic fistula occurred in $17 / 57(29.8 \%)$ of patients.

Table II shows a comparison of the pre- and intraoperative clinicopathological variables in the patients who underwent DP between the early-removal group $(n=19)$ and the conventional group $(n=38)$. Laparoscopic surgery, the rate of using a triple-row stapler, and the use of reinforcement were significantly higher in the early-removal group vs. the conventional group. There were no significant correlations between the two groups regarding age, sex, BMI, histological diagnosis, preoperative prognostic nutritional index, operative time, intraoperative blood loss volume, spleen preservation, thickness of the pancreatic transection line, and whether DP was combined with gastrectomy, colectomy, or enterectomy.

Regarding the postoperative surgical outcomes (Table III) between the early-removal group and the conventional group, the incidence of pancreatic fistula in the earlyremoval group was significantly lower than that in the 
Table III. Comparison of postoperative surgical outcomes in elderly patients undergoing distal pancreatectomy between the early drain removal group and the conventional drain removal group.

\begin{tabular}{|c|c|c|c|}
\hline Variables & $\begin{array}{l}\text { Early removal } \\
\text { group }(\mathrm{n}=19)\end{array}$ & $\begin{array}{l}\text { Conventional } \\
\text { group }(\mathrm{n}=38)\end{array}$ & $p$-Value \\
\hline Pancreatic fistula, $(\mathrm{n}, \%)$ & $2(10.5 \%)$ & $15(39.5 \%)$ & 0.022 \\
\hline Drain amylase level on POD $1^{\mathrm{a}}$, median (range), (IU/1) & $4,120(756-13,035)$ & $3,613(45-19,178)$ & 0.421 \\
\hline Drain amylase level on POD $3^{\text {b }}$, median (range), (IU/l) & $416(68-6,997)$ & $242(17-7,490)$ & 0.544 \\
\hline Serum C-reactive protein level on POD 1, median (range), (mg/dl) & $5.01(1.74-12.06)$ & $5.86(1.46-18.44)$ & 0.660 \\
\hline Serum C-reactive protein level on POD 1, median (range), (mg/dl) & $19.21(5.03-32.21)$ & $13.86(5.76-29.46)$ & 0.101 \\
\hline Positive bacterial smear test result on POD $3^{\mathrm{c}},(\mathrm{n}, \%)$ & $0(\%)$ & $1(2.9 \%)$ & 0.642 \\
\hline Duration of drain insertion, median (range), (days) & $4(3-4)$ & $6(3-148)$ & $<0.001$ \\
\hline Postoperative hospital stay, median (range), (days) & $18(10-52)$ & $22(11-151)$ & 0.036 \\
\hline $\begin{array}{l}\text { Postoperative fluid collection at the stump of the } \\
\text { remnant pancreas within } 90 \text { days after surgery }{ }^{\mathrm{d}},(\mathrm{n}, \%)\end{array}$ & $2(10.5 \%)$ & $3(8.3 \%)$ & 0.570 \\
\hline Readmission within 90 days after surgery, $(\mathrm{n}, \%)$ & $1(5.3 \%)$ & $0(0 \%)$ & 0.333 \\
\hline Mortality within 90 days after surgery, (n, \%) & $0(0 \%)$ & $0(0 \%)$ & N/A \\
\hline
\end{tabular}

POD, Postoperative day. ${ }^{a}$ Data for one patient not available; bdata for three patients not available; ${ }^{\mathrm{c}}$ data for four patients not available; ${ }^{\mathrm{d}}$ data for two patients not available. N/A: Not available. Continuous variables are expressed as median with range.

conventional group $(p=0.022)$. Additionally, the duration of drain insertion $(p<0.001)$ and postoperative hospital stay ( $p=0.036)$ were significantly shorter in the early-removal group $v s$. the conventional group. There were no significant differences in the drain amylase levels and serum C-reactive protein levels on POD 1 and 3 between the two groups. There were also no significant differences regarding the bacterial smear test results on POD 3, postoperative fluid collection at the stump of the remnant pancreas, and readmission within 90 days after surgery. There was no mortality within 90 days after surgery in either group.

Multivariate analysis revealed that early drain removal was an independent factor regarding reducing the risk of pancreatic fistula after DP in elderly patients ( $p=0.042$, Table IV).

\section{Discussion}

Increasing life expectancy is associated with a higher incidence of cancer (19). As a result, the rate of surgical resection in elderly patients has increased (1). However, elderly patients often have multiple comorbidities with functional impairment, tissue vulnerability, and are generally considered to have a high risk of postoperative complications after highly invasive surgery, such as pancreatectomy, which might cause protracted decline in their activities of daily living (20-23). Therefore, for elderly patients, safer surgical techniques or management to minimize complications following pancreatic resection, namely, pancreatic fistula, are required so that patients suffer no loss of independence or productivity. Studies limited to cohorts of only elderly patients are needed to evaluate elderly patients correctly because of large differences between elderly and younger patients regarding physiological function, such as organ dysfunction, or physical characteristics, such as frailty; thus, we designed this study to involve only elderly patients.

Early drain removal after pancreaticoduodenectomy effectively reduced the incidence of postoperative pancreatic fistula in one study (24). The study focused on postoperative surgical management and was based on the concept that longterm drain insertion may induce retrograde intraperitoneal infections that lead to postoperative pancreatic fistula. Additionally, in our previous report, a positive bacterial smear test early postoperatively was significantly associated with pancreatic fistula after pancreaticoduodenectomy (25). Regarding DP, a small number of reports have evaluated early $v s$. late drain removal. Adachi et al. discussed the possibility of a close relationship between intraperitoneal infection via the drain and subsequent pancreatic fistula, and concluded that early drain removal after DP provided favorable postoperative outcomes (26). Another study reported that late drain removal was significantly associated with complications after DP (15). Furthermore, Yang F et al. reported a close relationship between pancreatic fistula following DP and positive bacterial culture in the drainage fluid, and demonstrated that Staphylococcus spp. were isolated more frequently from the drainage fluid after DP (27). Therefore, pancreatic fistula following DP is considered to be caused by delayed drain removal that induces retrograde infection via the drainage tube. However, in these reports, the median age range of enrolled patients was 54-64 years, which is generally considered younger; therefore, the efficacy of early drain removal in elderly patients remains uncertain.

In the present study, which involved only elderly patients, we showed that early drain removal after DP decreased the incidence of postoperative pancreatic fistula, shortened the patients' postoperative hospital stay, and was not associated 
Table IV. Univariate and multivariate analyses of the risk factors for postoperative pancreatic fistula in elderly patients undergoing distal pancreatectomy.

\begin{tabular}{|c|c|c|c|c|c|c|}
\hline \multirow[b]{2}{*}{ Variables } & \multicolumn{3}{|c|}{ Univariate analysis } & \multicolumn{3}{|c|}{ Multivariate analysis } \\
\hline & Odds ratio & $95 \% \mathrm{CI}$ & $p$-Value & Odds ratio & $95 \% \mathrm{CI}$ & $p$-Value \\
\hline Age ( $\geq 80$ years $v s .<80$ years) & 0.639 & $0.174-2.348$ & 0.500 & & & \\
\hline Gender (male vs. female) & 1.950 & $0.536-7.088$ & 0.310 & & & \\
\hline Body mass index $(\geq 25$ vs. $<25)$ & 0.629 & 0.116-3.392 & 0.589 & & & \\
\hline Operative time ( $\geq 240 \mathrm{~min} v s .<240 \mathrm{~min})$ & 0.519 & $0.103-2.618$ & 0.427 & & & \\
\hline Blood loss volume ( $\geq 400 \mathrm{ml} v s .<400 \mathrm{ml}$ ) & 1.086 & $0.348-3.390$ & 0.886 & & & \\
\hline Surgical approach (laparoscopy vs. laparotomy) & 0.400 & $0.078-2.062$ & 0.273 & & & \\
\hline Stapler (triple-row $v s$. double-row) & 0.264 & $0.052-1.338$ & 0.108 & & & \\
\hline Reinforcement (present $v s$. absent) & 0.804 & $0.285-2.506$ & 0.707 & & & \\
\hline Combined with gastrectomy, colectomy, enterectomy (present $v s$. absent) & 5.846 & $0.956-35.738$ & 0.056 & 6.942 & $0.844-57.120$ & 0.072 \\
\hline Thickness of the pancreatic transection line $(\geq 11.4 \mathrm{~mm} v s .<11.4 \mathrm{~mm})$ & 4.000 & $1.176-13.603$ & 0.026 & 7.329 & $1.649-32.565$ & 0.009 \\
\hline Drain removal (early drain removal vs. conventional drain removal) & 0.180 & $0.036-0.896$ & 0.036 & 0.164 & $0.029-0.939$ & 0.042 \\
\hline
\end{tabular}

POD, Postoperative day; CI, confidence interval.

with mortality. In addition, no patients in the early-removal group had a positive bacterial smear test results in the drainage fluid. Consistent with previous reports in younger patients, our results support a relationship between retrograde drain infection and subsequent pancreatic fistula following DP in elderly patients.

As for reinforcement near the pancreatic stump, the reinforced stapler was reportedly reduced the incidence of pancreatic fistula after DP $(28,29)$. However, the usefulness of reinforced stapler to decrease pancreatic fistula could not be drawn in our study.

Regarding not placing a drainage tube after DP, a recent randomized multicenter controlled trial showed that clinical outcomes were comparable following DP with or without intraperitoneal drainage; however, the study also reported that the DP group without routine intraperitoneal drainage had a higher incidence of intra-abdominal fluid collection near the pancreatic stump (30). Another study reported that fluid collection volume was significantly associated with postoperative pancreatic fistula after DP (31). Moreover, no drain placement after DP was significantly associated with an increased risk of death or serious morbidity compared with early drain removal after DP (14). Therefore, the efficacy of omitting routine drainage in DP is controversial, especially for elderly patients.

In this study, early drain removal after DP was indicated to decrease postoperative pancreatic fistula safety and shorten hospital stay in elderly patients, so that the surgical procedure might contribute to maintain independence or productivity after DP for elderly patients. However, there were 2 patients that needed the reinsertion of an intraabdominal drain neat the pancreatic stump for postoperative pancreatic fistula. The risk factor for reinsertion of a drain to abdominal cavity could not be identified in this study.
Our study has several limitations. First, this was a retrospective analysis involving a small cohort, which can generate bias, although the cohort was composed of only elderly patients. Therefore, a prospective randomized multicenter trial is desirable to validate the efficacy of early drain removal after DP in elderly patients. Second, we defined early drain removal as removing the drain on POD 3 or 4 , while the optimal time for early removal after DP is unclear.

\section{Conclusion}

Early drain removal is useful and safer surgical perioperative management to decrease the risk of pancreatic fistula and to shorten the postoperative hospital stay in elderly patients undergoing DP.

\section{Conflicts of Interest}

The Authors declare that they have no conflicts of interest.

\section{Author's Contributions}

Study concept: Teruhisa Sakamoto. Study design: Teruhisa Sakamoto. Acquisition of data: Takuki Yagyu, Ei Uchinaka and Takehiko Hanaki. Analysis and interpretation of data: Kozo Miyatani and Kyoichi Kihara. Statistical analysis: Manabu Yamamoto, Tomoyuki Matsunaga and Naruo Tokuyasu. Drafting of manuscript: Teruhisa Sakamoto. Critical revision of manuscript: Soichiro Honjo and Yoshiyuki Fujiwara. Final approval of the article: all Authors.

\section{Acknowledgements}

The Authors would like to thank Jane Charbonneau, DVM, from Edanz Group (www.edanzediting.com/ac) for editing a draft of this manuscript. 


\section{References}

1 Etzioni DA, Liu JH, Maggard MA and Ko CY: The aging population and its impact on the surgery workforce. Ann Surg 238(2): 170-177, 2003. PMID: 12894008. DOI: 10.1097/01.SLA. $0000081085.98792 .3 \mathrm{~d}$

2 Tani M, Kawai M, Hirono S, Ina S, Miyazawa M, Nishioka R, Shimizu A, Uchiyama $\mathrm{K}$ and Yamaue H: A pancreaticoduodenectomy is acceptable for periampullary tumors in the elderly, even in patients over 80 years of age. J Hepatobiliary Pancreat Surg 16(5): 675-680, 2009. PMID: 19387530. DOI: 10.1007/s00534-009-0106-6

3 Oguro S, Shimada K, Kishi Y, Nara S, Esaki M and Kosuge T: Perioperative and long-term outcomes after pancreaticoduodenectomy in elderly patients 80 years of age and older. Langenbecks Arch Surg 398(4): 531-538, 2013. PMID: 23462741. DOI: 10.1007/s00423-013-1072-7

4 Sho M, Murakami Y, Kawai M, Motoi F, Satoi S, Matsumoto I, Honda G, Uemura K, Yanagimoto H, Kurata M, Akahori T, Kinoshita S, Nagai M, Nishiwada S, Fukumoto T, Unno M, Yamaue $\mathrm{H}$ and Nakajima Y: Prognosis after surgical treatment for pancreatic cancer in patients aged 80 years or older: a multicenter study. J Hepatobiliary Pancreat Sci 23(3): 188-197, 2016. PMID: 26763744. DOI: $10.1002 /$ jhbp. 320

5 Shamali A, De'Ath HD, Jaber B, Abuawad M, Barbaro S, Hamaday $\mathrm{Z}$ and Abu Hilal M: Elderly patients have similar short term outcomes and five-year survival compared to younger patients after pancreaticoduodenectomy. Int J Surg 45: 138-143, 2017. PMID: 28782662. DOI: 10.1016/j.ijsu.2017.07.106

6 Ohtsuka T, Nagakawa Y, Toyama H, Takeda Y, Maeda A, Kumamoto Y, Nakamura Y, Hashida K, Honda G, Fukuzawa K, Toyoda E, Tanabe M, Gotohda N, Matsumoto I, Ryu T, Uyama I, Kojima T, Unno M, Ichikawa D, Inoue Y, Matsukawa H, Sudo T, Takaori K, Yamaue H, Eguchi S, Tahara M, Shinzeki M, Eguchi H, Kurata M, Morimoto M, Hayashi H, Marubashi S, Inomata M, Kimura K, Amaya K, Sho M, Yoshida R, Murata A, Yoshitomi H, Hakamada K, Yasunaga M, Abe N, Hioki M, Tsuchiya M, Misawa T, Seyama Y, Noshiro H, Sakamoto E, Hasegawa K, Kawabata Y, Uchida Y, Kameyama S, Ko S, Takao T, Kitahara K, Nakahira S, Baba H, Watanabe M, Yamamoto $\mathrm{M}$ and Nakamura M: A multicenter prospective registration study on laparoscopic pancreatectomy in Japan: report on the assessment of 1,429 patients. J Hepatobiliary Pancreat Sci 27(2): 47-55, 2020. PMID: 31665567. DOI: 10.1002/jhbp.695

7 Jang JY, Shin YC, Han Y, Park JS, Han HS, Hwang HK, Yoon DS, Kim JK, Yoon YS, Hwang DW, Kang CM, Lee WJ, Heo JS, Kang MJ, Chang YR, Chang J, Jung W and Kim SW: Effect of polyglycolic acid mesh for prevention of pancreatic fistula following distal pancreatectomy: a randomized clinical trial. JAMA Surg 152(2): 150-155, 2017. PMID: 27784046. DOI: 10.1001/jamasurg.2016.3644

8 de Rooij T, van Hilst J, van Santvoort H, Boerma D, van den Boezem P, Daams F, van Dam R, Dejong C, van Duyn E, Dijkgraaf M, van Eijck C, Festen S, Gerhards M, Groot Koerkamp B, de Hingh I, Kazemier G, Klaase J, de Kleine R, van Laarhoven C, Luyer M, Patijn G, Steenvoorde P, Suker M, Abu Hilal M, Busch O and Besselink M; Dutch Pancreatic Cancer Group: Minimally invasive versus open distal pancreatectomy (LEOPARD): a multicenter patient-blinded randomized controlled trial. Ann Surg 269(1): 2-9, 2019. PMID: 30080726. DOI: 10.1097/SLA.0000000000002979

9 Cecka F, Jon B, Subrt Z and Ferko A: Clinical and economic consequences of pancreatic fistula after elective pancreatic resection. Hepatobiliary Pancreat Dis Int 12(5): 533-539, 2013. PMID: 24103285. DOI: 10.1016/s1499-3872(13)60084-3

10 Montorsi M, Zerbi A, Bassi C, Capussotti L, Coppola R and Sacchi M; Italian Tachosil Study Group: Efficacy of an absorbable fibrin sealant patch (TachoSil) after distal pancreatectomy: a multicenter, randomized, controlled trial. Ann Surg 256(5): 853-859; discussion 859-860, 2012. PMID: 23095631. DOI: $10.1097 /$ SLA.0b013e318272dec0

11 Hassenpflug M, Hinz U, Strobel O, Volpert J, Knebel P, Diener MK, Doerr-Harim C, Werner J, Hackert T and Büchler MW: Teres ligament patch reduces relevant morbidity after distal pancreatectomy (the DISCOVER Randomized Controlled Trial). Ann Surg 264(5): 723-730, 2016. PMID: 27455155. DOI: 10.1097/SLA.0000000000001913

12 Kawai M, Hirono S, Okada K, Sho M, Nakajima Y, Eguchi H, Nagano H, Ikoma H, Morimura R, Takeda Y, Nakahira S, Suzumura K, Fujimoto J and Yamaue H: Randomized controlled trial of pancreaticojejunostomy versus stapler closure of the pancreatic stump during distal pancreatectomy to reduce pancreatic fistula. Ann Surg 264(1): 180-187, 2016. PMID: 26473652. DOI: 10.1097/SLA.0000000000001395

13 Kondo N, Uemura K, Nakagawa N, Okada K, Kuroda S, Sudo T, Hadano N, Matstukawa H, Satoh D, Sasaki M, Abe T, Fukuda S, Oshita A, Nakashima A, Hashimoto Y, Ohdan H and Murakami Y; Hiroshima Surgical Study Group of Clinical Oncology: A multicenter, randomized, controlled trial comparing reinforced staplers with bare staplers during distal pancreatectomy (HiSCO07 Trial). Ann Surg Oncol 26(5): 1519-1527, 2019. PMID: 30783854. DOI: 10.1245/s10434-019-07222-0

14 Seykora TF, Liu JB, Maggino L, Pitt HA and Vollmer CM Jr: Drain management following distal pancreatectomy: Characterization of contemporary practice and impact of early removal. Ann Surg, 2019. PMID: 30943185. DOI: 10.1097/SLA.0000000000003205

15 Villafane-Ferriol N, Baugh KA, McElhany AL, Van Buren G 2nd, Fang A, Tashakori EK, Reyes JEM, Cao HST, Silberfein EJ, Massarweh N, Hsu C, Barakat O, Schmidt C, Zyromski NJ, Dillhoff M, Villarreal JA and Fisher WE: Evidence versus practice in early drain removal after pancreatectomy. J Surg Res 236: 332339, 2019. PMID: 30694774. DOI: 10.1016/j.jss.2018.11.048

16 Baider L and Surbone A: Universality of aging: family caregivers for elderly cancer patients. Front Psychol 5: 744, 2014. PMID: 25076927. DOI: 10.3389/fpsyg.2014.00744

17 Sahakyan MA, Edwin B, Kazaryan AM, Barkhatov L, Buanes T, Ignjatovic D, Labori KJ and Røsok BI: Perioperative outcomes and survival in elderly patients undergoing laparoscopic distal pancreatectomy. J Hepatobiliary Pancreat Sci 24(1): 42-48, 2017. PMID: 27794204. DOI: 10.1002/jhbp.409

18 Bassi C, Marchegiani G, Dervenis C, Sarr M, Abu Hilal M, Adham M, Allen P, Andersson R, Asbun HJ, Besselink MG, Conlon K, Del Chiaro M, Falconi M, Fernandez-Cruz L, Fernandez-Del Castillo C, Fingerhut A, Friess H, Gouma DJ, Hackert T, Izbicki J, Lillemoe KD, Neoptolemos JP, Olah A, Schulick R, Shrikhande SV, Takada T, Takaori K, Traverso W, Vollmer CR, Wolfgang CL, Yeo CJ, Salvia R and Buchler M; International Study Group on Pancreatic Surgery (ISGPS): The 
2016 update of the International Study Group (ISGPS) definition and grading of postoperative pancreatic fistula: 11 Years After. Surgery 161(3): 584-591, 2017. PMID: 28040257. DOI: 10.1016/j.surg .2016.11.014

19 Global, regional, and national disability-adjusted life-years (DALYs) for 359 diseases and injuries and healthy life expectancy (HALE) for 195 countries and territories, 1990-2017: a systematic analysis for the Global Burden of Disease Study 2017. Lancet 392(10159): 1859-1922, 2018. PMID: 30415748. DOI: $10.1016 / \mathrm{S} 0140-6736(18) 32335-3$

20 Wiltberger G, Muhl B, Benzing C, Hau HM, Bartels M and Krenzien F: Pancreaticoduodenectomy in the elderly patient: Age-adapted risk assessment. Dig Surg 34(1): 43-51, 2017. PMID: 27434057. DOI: 10.1159/000448059

21 Nagle RT, Leiby BE, Lavu H, Rosato EL, Yeo CJ and Winter JM: Pneumonia is associated with a high risk of mortality after pancreaticoduodenectomy. Surgery 161(4): 959-967, 2017. PMID: 27836210. DOI: 10.1016/j.surg.2016.09.028

22 Aoki S, Miyata H, Konno H, Gotoh M, Motoi F, Kumamaru H, Wakabayashi G, Kakeji Y, Mori M, Seto Y and Unno M: Risk factors of serious postoperative complications after pancreaticoduodenectomy and risk calculators for predicting postoperative complications: a nationwide study of 17,564 patients in Japan. J Hepatobiliary Pancreat Sci 24(5): 243-251, 2017. PMID: 28196308. DOI: 10.1002/jhbp. 438

23 Amemiya T, Oda K, Ando M, Kawamura T, Kitagawa Y, Okawa Y, Yasui A, Ike H, Shimada H, Kuroiwa K, Nimura Y and Fukata S: Activities of daily living and quality of life of elderly patients after elective surgery for gastric and colorectal cancers. Ann Surg 246(2): 222-228, 2007. PMID: 17667500. DOI: 10.1097/SLA.0b013e3180caa3fb

24 Kawai M, Tani M, Terasawa H, Ina S, Hirono S, Nishioka R, Miyazawa M, Uchiyama K and Yamaue H: Early removal of prophylactic drains reduces the risk of intra-abdominal infections in patients with pancreatic head resection: prospective study for 104 consecutive patients. Ann Surg 244(1): 1-7, 2006. PMID: 16794381. DOI: 10.1097/01.sla.0000218077.14035.a6

25 Morimoto M, Honjo S, Sakamoto T, Yagyu T, Uchinaka E, Amisaki M, Watanabe J, Yamamoto M, Fukumoto Y, Tokuyasu N, Ashida K, Saito H and Fujiwara Y: Bacterial smear test of drainage fluid after pancreaticoduodenectomy can predict postoperative pancreatic fistula. Pancreatology 19(2): 274-279, 2019. PMID: 30718188. DOI: 10.1016/j.pan.2019.01.018

26 Adachi T, Kuroki T, Kitasato A, Hirabaru M, Matsushima H, Soyama A, Hidaka M, Takatsuki M and Eguchi S: Safety and efficacy of early drain removal and triple-drug therapy to prevent pancreatic fistula after distal pancreatectomy. Pancreatology 15(4): 411-416, 2015. PMID: 26073457. DOI: 10.1016/j.pan.2015.05.468
27 Yang F, Jin C, Hao S and Fu D: Drain contamination after distal pancreatectomy: Incidence, risk factors, and association with postoperative pancreatic fistula. J Gastrointest Surg 23(12): 2449-2458, 2019. PMID: 30815778. DOI: 10.1007/s11605-01904155-7

28 Kawaida H, Kono H, Amemiya H, Hosomura N, Saito R, Takahashi K, Yamamoto A, Watanabe M, Furuya S, Shimizu H, Akaike H, Kawaguchi Y, Sudo M, Matusda M, Itaklura J, Fujii $\mathrm{H}$ and Ichikawa D: Use of a reinforced triple-row stapler following distal pancreatectomy reduces the incidence of postoperative pancreatic fistula in patients with a high BMI. Anticancer Res 39(2): 1013-1018, 2019. PMID: 30711989. DOI: 10.21873/anticanres.13207

29 Yamashita Y,Tsujita E, Chikamoto A, Imai K, Kaida T, Yamao T, Umezaki N, Nakawata S, Hashimoto D and Baba H: Linear stapling device with pre-attached bioabsorbable polyglycolic acid felt reduces postoperative pancreatic fistula after distal pancreatectomy. Anticancer Res 37(4): 1865-1868, 2017. PMID: 28373453. DOI: 10.21873 /anticanres.11523

30 Van Buren G 2nd, Bloomston M, Schmidt CR, Behrman SW, Zyromski NJ, Ball CG, Morgan KA, Hughes SJ, Karanicolas PJ, Allendorf JD, Vollmer CM Jr, Ly Q, Brown KM, Velanovich V, Winter JM, McElhany AL, Muscarella P 2nd, Schmidt CM, House MG, Dixon E, Dillhoff ME, Trevino JG, Hallet J, Coburn NSG, Nakeeb A, Behrns KE, Sasson AR, Ceppa EP, AbdelMisih SRZ, Riall TS, Silberfein EJ, Ellison EC, Adams DB, Hsu C, Tran Cao HS, Mohammed S, Villafañe-Ferriol N, Barakat O, Massarweh NN, Chai C, Mendez-Reyes JE, Fang A, Jo E, Mo $\mathrm{Q}$ and Fisher WE: A prospective randomized multicenter trial of distal pancreatectomy with and without routine intraperitoneal drainage. Ann Surg 266(3): 421-431, 2017. PMID: 28692468. DOI: $10.1097 / S L A .0000000000002375$

31 Yoshino J, Ban D, Ogura T, Ogawa K, Ono H, Mitsunori Y, Kudo A, Tanaka S and Tanabe M: The clinical implications of peripancreatic fluid collection after distal pancreatectomy. World J Surg 43(8): 2069-2076, 2019. PMID: 31004209. DOI: $10.1007 / \mathrm{s} 00268-019-05009-8$
Received June 23, 2020

Revised July 10, 2020

Accepted July 13, 2020 